\title{
Gender Stereotyping in Children's Reports About Educational and Informational Television Programs
}

\author{
Sandra L. Calvert \\ Department of Psychology \\ Georgetown University \\ Jennifer A. Kotler \\ National Center for Children and Poverty \\ Columbia University \\ Sean M. Zehnder \\ Erin M. Shockey \\ Department of Psychology \\ Georgetown University
}

Children in the 2nd through 6th grade wrote reports about their favorite educational and informational television programs, and the reports were examined for the presence of gender stereotypes. Children's written reports contained more male than female characters, more male than female pronouns, and more masculine than feminine behaviors. Effects were most pronounced for boys. Over time, preadolescent girls showed a greater preference for educational programs that featured female lead characters, and the girls used more feminine pronouns, behaviors, and expressed a greater range of feelings in their writings about their favorite programs. Girls and boys, however, were more likely to report masculine behaviors for male and female characters. Moreover, gender-stereotyping effects were eliminated for boys who selected a favorite program featuring an adventurous female lead character. Although memories of educational television programs are often gender stereotyped, a few nontraditional programs can drench the audience, providing nontraditional images and models for those who search for them.

Requests for reprints should be sent to Sandra Calvert, Children's Digital Media Center, Department of Psychology, Georgetown University, 37th \& O Streets, N.W., Washington, D.C. 20057.E-mail: calverts@georgetown.edu 
The world of children's television has many gender stereotypes. Content analyses of television programs have long documented pervasive gender stereotyping in the number of male and female characters portrayed, the kinds of behaviors enacted, and the emotional modes of expression used by characters (Calvert, 1999). Although television content is but a microcosm of the general culture, such portrayals serve to reinforce gender-stereotyped values and behaviors.

Television, though, also has the capacity to alter the kinds of beliefs that children hold about males and females and their beliefs about what constitutes appropriate behaviors for the two genders. Because the Children's Television Act of 1990 requires broadcasters to provide educational and informational television programs for children, it is possible that prosocial values, including the reduction of gender stereotypes, may be more prevalent in the content of children's media. Although content analyses reveal that many of the educational and informational programs are also gender stereotyped (Barner, 1999; Calvert, Stolkin, \& Lee, 1997), even a few non-gender-stereotyped programs have the potential to support nontraditional beliefs about gender.

Portrayals of gender must also be filtered through a child's cognitive processing system, including his or her beliefs and expectations about gender. American culture strongly pressures boys to adhere to traditional masculine behaviors (Ruble \& Martin, 1998). How do such cultural pressures, combined with content that is often gender stereotyped, influence children's memories of the educational television programs they view?

The purpose of this study was to examine the kinds of gender-related information that children remember about their favorite educational television programs. Our main hypothesis was that both boys and girls would include gender-stereotyped content in their reports, but that boys would show stronger gender-stereotyped patterns than would girls.

\section{CONTENT ANALYSES OF CHILDREN'S TELEVISION PROGRAMS}

One way that researchers examine the relative importance of men and women involves counting the number of men and women portrayed in a television program, particularly as a major character with a speaking role. Although there are approximately equal numbers of men and women in the American population, male characters consistently outnumber female characters 3:1 in television pro- 
gramming (Calvert \& Huston, 1987), including children's educational programs (Calvert et al., 1997). In one study of children's educational television programs, male characters actually spent more time speaking than female characters spent on the screen (Calvert et al., 1997). Although Barner (1999) did not find that male characters significantly outnumbered female characters in a sample of educational and informational television programs, he did find that there were no educational and informational programs with a female central character. These distortions of number are important because they are a relative display of power, of who counts in American society, and, by the same measure, of who does not count (Gerbner, 1996).

Barner (1999) also found that males engaged in a wider range of behaviors in educational television programs than did females. The kinds of behaviors expressed by male and female television characters often reflected gender stereotypes. Specifically, male characters were depicted as more active, constructive, dominant, aggressive, and attention seeking (i.e., calling attention to oneself and one's achievements); whereas female characters were depicted as more deferent, dependent, and nurturant (Barner, 1999).

General audience action-adventure programs, which are typically the domain of male characters, may accentuate these differences, though nontraditional female heroic portrayals can moderate these effects. For example, women who perceived a female action hero as a role model also perceived her as being more in control of her life, as nurturing, and as physically attractive; whereas men who perceived her as a role model found her to be nurturing (Calvert, Kondla, Ertel, \& Meisel, 2001). In general, heroic roles and instrumental helping (e.g., rescuing others) are more consistent with the male role than the female role (Eagly \& Crowley, 1986), and boys prefer superhero roles more so than do girls (Ruble \& Martin, 1998). Even so, compassion is considered to be an important quality of heroic role models, be they male or female (Calvert et al., 2001; Zehnder, 2002). Nonetheless, boys view action-adventure heroic programs more than do girls (Huston, Wright, Rice, Kerkman, \& St. Peters, 1990). Therefore boys, more so than girls, may have more opportunities to observe and to identity with heroic role models.

Finally, the affective qualities of male and female characters may well reflect gender stereotypes. In particular, men are typically taught to control their feelings, and if they do express their feelings they should be strong feelings, like anger (Ruble \& Martin, 1998). By early elementary school, boys begin to conceal weak emotions, like sadness, while girls begin to conceal anger (Ruble \& Martin, 1998). As they grow older, girls also report more intense emotional reactions to experiences than do boys (Ruble \& Martin, 1998). 


\section{SCHEMATIC PROCESSING OF TELEVISION PROGRAMS}

Children's processing of television programs is an active process, guided by learned expectations that guide perception, memory, and inferences about the content they view (Calvert \& Huston, 1987). These learned expectations, or schemas, include gender-linked information. A very simple type of gender schema is a gender stereotype.

Gender schemas play a particularly important role in children's lives because they serve as early organizers of experience and self-definition (Martin \& Halverson, 1981). Gender schemas can serve as guides for what children do and don't do and for what children find to be acceptable and unacceptable behaviors.

Because the male role is valued more in American society than is the female role, males come under greater pressure to behave in gender-stereotyped ways (Ruble \& Martin, 1998). For instance, boys are taught not to cry and not to express tender affect (Huston, 1983). They are encouraged to be rough in athletic pursuits and to be competitive and tough. By contrast, girls are encouraged to express their feelings and to act in polite ways. Because the female role is often devalued, girls have more flexibility to act in traditionally masculine ways than boys have to act in traditionally feminine ways (Ruble \& Martin, 1998). For instance, girls and boys who are labeled a tomboy and a sissy are perceived very differently in American culture (Martin, 1990).

Gender constancy, when boys and girls understand the immutable underlying genetic nature of their sex, marks a change in boys' behaviors (Kohlberg, 1966). At about age 7, when boys understand they will always be male, they increasingly view television programs with male characters, they pay more attention to these male characters, and they watch more sports programs (Luecke-Aleksa, Anderson, Collins, \& Schmitt, 1995). Girls, by contrast, do not show such changes in attention after gender constancy is achieved. Such differences have led to programming practices, such as showing more male than female characters, because producers believe that boys care about the gender of their main characters more than do girls (Jordan, 1996).

Girls, however, do show gender-related preferences in their program selections. For instance, girls are less likely than boys to watch action-adventure programs or cartoons featuring violent content (Huston et al., 1990), programs that often feature heroic portrayals (Wilson et al., 2002). Girls also enjoy educational content, particularly programs containing social and emotional themes, more than do boys (Calvert et al., 2002). For this study, we selected children who should have achieved gender constancy and divided the children into a younger age 
group (8-10 years) and an older age group (11-12 years). We wanted to see if any differences existed in the children's gender stereotyping during the middlechildhood years because there are additional age differences in comprehension of television programming during these years. Specifically, as children age, they increasingly understand the feelings and motives of characters (Calvert, 1999).

Gender schemas also influence how children remember televised content. For instance, children who saw a male nurse and a female doctor later remembered a male doctor and a female nurse (Cordua, McGraw, \& Drabman, 1979). Similarly, gender-stereotyped children who saw a traditional television program where a woman was portrayed as a wife and mother remembered the program better than they remembered a nontraditional program about a woman who was portrayed as a female surgeon and an army officer. Non-gender-stereotyped children, by contrast, remembered both kinds of portrayals well (List, Collins \& Westby, 1983).

Given that gender schemas influence children's memories of television programs, we wondered how they would remember the educational and informational television programs that they selected as favorites. We think that favorite programs may have a greater influence on children because they may be more attentive to those programs, they may remember them better, and they may be more likely to relate that information to their own lives. If favorite programs are stable over time, these effects should be even more pronounced.

\section{THE DRIP AND DRENCH HYPOTHESES}

The drip and drench hypotheses have been used to explain the impact of television viewing on viewers' beliefs (Greenberg, 1988). In the drip hypothesis, the steady drip of gender-stereotyped images reinforces and cultivates genderstereotyped beliefs and values. In this hypothesis, gender-stereotyped content is a dominant image in the media.

By contrast, the drench hypothesis suggests that a few nontraditional images can alter gender values and beliefs (Greenberg, 1988). Thus, the presentation of even one strong minority portrayal could lead to important inroads in audience perceptions of men and women. Although the drip and drench hypotheses are potentially useful in understanding the impact of gender-stereotyped media on children, we believe that the paucity of female images in television productions makes the drench hypothesis a useful framework for examining potential ways to provide nontraditional content for viewers. More specifically, television programs that violate stereotyped norms, such as an adventurous televised girl character like Eliza Thornberry, could provide useful information about whether the 
drench hypothesis accurately describes a mechanism for fostering memories of nontraditional gender roles.

\section{HYPOTHESES}

The purpose of this study was to describe gender-linked information that children wrote about their favorite educational and informational television programs. We expected evidence of gender stereotyping in the reports of girls and boys, but we also expected gender stereotyping to be more pronounced in boys' reports. In particular, we expected boys to report more male characters, more male pronouns, more masculine behaviors, and fewer feelings than girls; whereas we expected girls to report more female characters, more female pronouns, more feminine behaviors, and more feelings than boys. We also expected older children to report more characters, pronouns, behaviors, and feelings than younger children. Finally, we expected boys and girls to select a same-sex model as the editor of choice for sending their reports.

\section{METHOD}

\section{Participants}

Participants were part of a larger study that examined what second- through sixthgrade children were learning from educational and informational television programs (see Calvert \& Kotler, in press). In the larger study, three waves of data were collected during the 1999 to 2000 viewing season. In this study, 318 children (192 second through fourth graders and 126 fifth through sixth graders) who provided first reports from Wave 1 (October-December, 1999) and first reports from Wave 3 (April-June, 2000) were examined. There were 173 girls and 145 boys.

\section{Procedure}

Children participated in our online study through our Web site, http://data. georgetown.edu/kidtv. The participants were from 13 schools in various locations throughout the United States. The schools represented a wide range of socioeconomic and ethnic groups, ranging from inner city, minority youths (primarily African American); to suburban, middle-class youths (primarily White); to rural, middle-class youth (primarily White); to small city youths (African American and 
White). The children lived in New York, Connecticut, Maryland, Arkansas, California, Colorado, Utah, Tennessee, Texas, and Pennsylvania. A convenience sampling method was used to locate schools that were willing to participate.

Our Internet site was structured as a game, and the children came online as Georgetown Hoya Reporters, a reference to our home university and to the activity in which the children participated. Specifically, the children came online as reporters from their classrooms once per month for most of the school year. We used the children's first reports of the first wave of data collection (OctoberDecember, 1999), and the children's first reports of the third wave of data collection (April-June, 2000) in our sample.

As reporters, children came online and told us about their viewing of educational and informational programs during the previous week. First, children clicked on programs on our site (a) that the four major broadcasters (ABC, CBS, $\mathrm{NBC}$, and FOX) had designated as educational and informational or (b) that our research team had designated as educational and informational by viewing samples of programming for the middle-childhood audience that were broadcast on Nickelodeon and PBS.

After the children selected the programs that they had viewed, our computer program (written in Microsoft Access, Cold Fusion, HTML, and Java Script) advanced the children to another page where only the programs they had viewed were posted. From those programs, the children selected their favorite program of the week. With the selection of their favorite program, the screen advanced to another page where the children were asked to write a report about their favorite program. Specifically, the children were asked to pretend that they were writing to a friend who had not seen the program and to tell that friend what the program was about as well as what they had learned from watching the program. That report was the focus of this study. Finally, the children posted their reports to either an online male or female animated editor named Will or Kate.

\section{Educational and Informational Television Programs}

For the 1999-2000 season, our 32 target programs for second- through sixthgrade children were as follows:

- ABC: Brand Spanking New! Doug, Disney's Pepper Ann, Disney's Recess, Squigglevision, Sabrina, the Animated Witch, and The Weekenders

- CBS: Anatole, Flying Rhinos Junior High, Mythic Warriors, Rescue Heroes, Blaster's Universe, and Secrets of the Cryptkeeper

- FOX: The Magic School Bus and Sherlock Holmes in the 22nd Century 
- NBC: City Guys, Hang Time, New Saved by the Bell, NBA Inside Stuff, and One World

- PBS: Bill Nye the Science Guy, Wishbone, Kratts' Creatures, and Zoom

- Nickelodeon: Hey Arnold!, Doug, My Brother and Me, Shelby Woo, The Secret World of Alex Mack, Nick News, Clarissa Explains It All, Cousin Skeeter, and The Wild Thornberrys

During the year, Nickelodeon dropped Clarissa Explains It All, My Brother and $M e$, and Shelby Woo from their schedule, and hence we dropped them from our sample in Wave 3. The Weekenders began airing on $\mathrm{ABC}$ stations and was added to our site in Wave 3. Bill Nye the Science Guy originally aired on PBS stations but was broadcast on various commercial stations, including FOX in Wave 3, and therefore became a broadcast program. In Wave 1 there were 18 commercial broadcaster programs and 13 Nickelodeon and PBS programs. In Wave 3, there were 20 commercial broadcaster programs and only 9 Nickelodeon/ PBS programs.

\section{Dependent Variables}

Our dependent variables were (a) the number of distinct male and female characters identified in each report, (b) the overall number of male and female pronouns used in each report, (c) the kinds of gender-stereotyped behaviors and traits identified in the reports, (d) the number of feelings identified in the reports; and (e) the gender of the online animated editor that the children selected to send their reports.

Number of male and female characters in children's reports. To determine the gender of the characters reported by the children, we counted the number of distinct male and female characters that the children wrote about in each of their reports. Each character was counted only once, even if that name appeared more than one time. This kind of index gave a direct comparison to the relative number of male and female characters typically found in children's television programs. If gender could not be determined from knowledge about the story or subsequent pronoun use, the character was coded as neutral. Groups of characters were also considered to be gender neutral. Because animal names are often gender neutral (e.g., Wishbone), pets and animal characters were scored as gender neutral unless the child labeled the animal as male or female at some point in the report. 
Reliability was scored for $20 \%$ of the reports. Interrater reliability, calculated as an exact agreement between Scorer 1 and Scorer 2, was 83\% for male characters (Scott's pi $=.75$ ) and 92\% for female characters (Scott's pi $=.88$ ). Primarily, errors involved scoring the gender of an animal character (e.g., scoring the dog Wishbone as a male) if the child did not indicate that knowledge elsewhere in the report but the scorer knew the gender of the animal.

Number of masculine and feminine pronouns in children's reports. Next, we counted the total number of masculine and feminine pronouns that the children used in their reports. Personal pronouns had to refer to a character that the children had previously identified in their report. Masculine pronouns included he and him; feminine pronouns included she and her. We counted every incidence of pronoun use, which enabled us to measure the relative focus of the children's reports on males and females. Possessive pronouns, such as his dad, were not counted. The pronoun they was scored as gender neutral.

Reliability was scored for $20 \%$ of the reports. Interrater reliability, based on an exact agreement between Scorer 1 and Scorer 2, was 89\% (Scott's pi $=.77$ ) for masculine pronouns and $91 \%$ (Scott's pi $=.77$ ) for feminine pronouns. Scorers sometimes erroneously included a possessive pronoun in their count.

Number of masculine and feminine behaviors and traits in children's reports. Coding gender-stereotyped behaviors followed two steps. First, each report was broken into unique segments so that each noun-verb clause could be coded for gender stereotyping. A reliability correlation coefficient was computed between two coders on $20 \%$ of the data to assess whether coders agreed on the number of segments that were present in the reports. Agreement was significantly correlated at $\sigma=0.98, p<.001$.

Once each noun-verb clause was segmented within each report, the data were then coded for incidences of gender-stereotyped behaviors and traits. For each segment, the coders made a decision as to whether the action-behavior-trait of the characters were (a) traditionally masculine or (b) traditionally feminine. One masculine subcategory, involving heroic activities, was also analyzed separately.

Masculine and feminine behaviors were derived from (a) gender stereotyped personality characteristics adapted from the Bem Sex-Role Inventory (Bem, 1981) and (b) gender-stereotyped behaviors identified by researchers who had conducted content analyses of television programs (Barner, 1999; Sternglanz \& Serbin, 1974). The dictionary was our major resource for defining the specific terms in the Bem Sex-Role Inventory. 
The terms for behaviors and traits in the masculine category were analytic, "to study in a critical, logical manner" (New Webster's Comprehensive Dictionary, 1985 , p. 37); autonomous, to resist influence or coercion; to defy an authority or seek freedom; to strive for independence (Barner, 1999, p. 557; Sternglanz \& Serbin, 1974, p. 712); independent, "acting and thinking for oneself; not relying upon a larger unit or group" (New Webster's Comprehensive Dictionary, 1985 , p. 488); athletic, "strong, robust, active, vigorous" (New Webster's Comprehensive Dictionary, 1985, p. 63); dominant, to influence or control others; to dictate, prohibit; to lead, direct, restrain; to organize the behavior of a group (Barner, 1999, p. 557; Sternglanz \& Serbin, 1974, p. 712); aggressive, to assault or injure purposely; to harm, blame, ridicule, threaten, use sarcasm (Barner, 1999, p. 557; Sternglanz \& Serbin, 1974, p. 712); ambitious, "desiring power, fame, honor, office, superiority, or distinction" (New Webster's Comprehensive Dictionary, 1985 , p. 32); competitive, "a trial of skill or a contest proposed as a test of fitness or superiority" (New Webster's Comprehensive Dictionary, 1985, p. 206); and heroic, "valor, bravery, boldness, daring" (New Webster's Comprehensive Dictionary, 1985, p. 451), and rescue of others at personal risk (Calvert et al., 2001).

The terms for behaviors and traits in the feminine category were shy, "reserved, retiring, modest, self-conscious, timid" (New Webster's Comprehensive Dictionary, 1985 , p. 896); harm avoidant, tendency to avoid physical pain; to withdraw or flee from injury (Barner, 1999, p. 557; Sternglanz \& Serbin, 1974, p. 712); romantic, "amorous, ardent, love interests" (New Webster's Comprehensive Dictionary, 1985, p. 833); deferent, to follow directions or example of leader; to imitate; to admire or compliment (Barner, 1999, p. 557; Sternglanz \& Serbin, 1974, p. 712); yielding, "ready to submit, compliant, unresisting" (New Webster's Comprehensive Dictionary, 1985, p. 1154); dependent, to seek aid, protection, sympathy, or information to carry out a project; to cry for help (Barner, 1999, p. 557; Sternglanz \& Serbin, 1974, p. 712); affectionate, “fond, loving, tender" (New Webster's Comprehensive Dictionary, 1985, p. 19); warm, "cordial, intimate” (New Webster's Comprehensive Dictionary, 1985, p. 1119); gentle, "kindly, amiable" (New Webster's Comprehensive Dictionary, 1985, p. 405); compassionate, "merciful, charitable" (New Webster's Comprehensive Dictionary, 1985, p. 206); and body conscious, concerned about physical appearance or physical well-being (Northrup, 1994).

We collapsed these behaviors and traits into two categories. Masculine behaviors and traits were comprised of dominant-aggressive; autonomous-independent; analytic; competitive-ambitious; athletic; and heroic (rescue). Feminine behaviors and traits were comprised of deferent-yielding-dependent; affectionate-warmgentle-compassionate; romantic; body conscious; harm avoidant; and shy. 
Reliability was coded for $20 \%$ of the reports for the presence versus absence of both masculine and feminine behaviors and traits and for the gender of the character performing the behavior. Across segments, interrater reliability, calculated as exact agreement, was $85 \%$ for the presence versus absence of masculine behaviors and traits, $93 \%$ for the presence versus absence of feminine behaviors and traits, and $85 \%$ for the gender of the character performing the behavior.

Number of feelings in children's reports. We recorded the children's use of specific emotions in their reports. We then grouped those feelings into the areas of love, happiness, surprise, anger, sadness, and fear. Each expression of an emotion was counted. Reliability was calculated for $20 \%$ of the reports. Interobserver reliability, calculated as an exact agreement for the specific emotion found in children's reports, was $85 \%$ (Scott's pi $=.78$ ).

Gender of character for reporting. Children sent their reports to Will or Kate, the two animated-editor characters on our Web site. To do so, the children clicked on one of the character names when they sent their report.

\section{RESULTS}

\section{Favorite Programs}

Reports were based on the children's favorite programs. Overall, boys and girls chose the same educational television programs as favorites, and these programs were consistent over time. Younger girls selected (a) Hey Arnold!; (b) The Wild Thornberrys; (c) Brand Spanking New! Doug; (d) Sabrina, the Animated Witch; and (e) Disney's Recess as favorite programs in Wave 1. Their choices for favorite programs in Wave 3 were the same except that Sabrina, the Animated Witch and Disney's Recess changed positions. Older girls selected (a) Hey Arnold!; (b) Disney's Recess; (c) The Wild Thornberrys; (d) Sabrina, the Animated Witch; and (e) Brand Spanking New! Doug in Wave 1. In Wave 3, older girls' favorite programs increasingly emphasized female leads: (a) Hey Arnold!; (b) The Wild Thornberrys; (c) Disney's Pepper Ann; (d) Sabrina, the Animated Witch; and (e) Brand Spanking New! Doug.

For younger boys, the favorite programs were (a) Hey Arnold!, (b) Brand Spanking New! Doug, (c) Cousin Skeeter, (d) Disney's Recess, and (e) The Wild Thornberrys in Wave 1. In Wave 3, younger boys selected (a) Hey Arnold!, (b) The Wild Thornberrys, (c) Disney's Recess, (d) Brand Spanking New! Doug, and 
(e) Cousin Skeeter. Older boys selected (a) Hey Arnold!, (b) Brand Spanking New! Doug, (c) Disney's Recess, (d) Cousin Skeeter, and (e) The Wild Thornberrys in Wave 1. By Wave 3, older boys selected (a) Hey Arnold!, (b) The Wild Thornberrys, (c) Cousin Skeeter, (d) Disney's Recess, and (e) Brand Spanking New! Doug.

The Wild Thornberrys features a female lead character and became increasingly popular with boys and girls over time. Hey Arnold! and Brand Spanking New! Doug feature male lead characters, and Disney's Recess is a mixed-gender program; all are popular with both genders. Cousin Skeeter is a predominantly male cast, popular primarily with boys; whereas Sabrina, the Animated Witch and Disney's Pepper Ann feature female lead characters popular primarily with girls.

\section{Reporters' Writing About Male and Female Characters}

In order to examine whether boys and girls differed in their use of male versus female characters in their reports, a 2 (gender) $\times 2$ (grade) $\times 2$ (wave) $\times 2$ (character type: male and female) mixed analysis of variance (ANOVA) was conducted with number of characters reported as the dependent variable. Gender and grade were the between-subjects factors. Character type and wave were the within-subject factors.

The 4-factor ANOVA computed on character type yielded main effects of age, $F(1,314)=11.248, p<.01, \eta_{\mathrm{p}}^{2}=.035$; and character type, $F(1,314)=46.858$, $p<.001, \eta_{\mathrm{p}}{ }^{2}=.130$. Older children reported more unique characters in their reports than younger children $(M=1.77, S D=1.13$ vs. $M=1.36, S D=0.99)$. Children's reports contained more male $(M=0.92, S D=0.78)$ than female characters $(M=0.60, S D=0.60)$.

The main effect of character type was qualified by a significant Character $X$ Gender interaction, $F(1,314)=17.131, p<.001, \eta_{\mathrm{p}}^{2}=.052$. Follow-up analyses revealed that there were no significant differences between boys' and girls' reports in the number of male characters. However, girls' reports contained significantly more female characters than did boys' reports $(M=0.73, S D=0.64$ vs. $M=0.43, S D=0.51)$. An additional follow-up analysis indicated that even though the difference for the girls was smaller, both boys and girls reported significantly more male than female characters (boys: $M=0.97, S D=0.81$ vs. $M=0.43, S D=0.51$; girls: $M=0.88, S D=0.76$ vs. $M=0.73, S D=0.64)$.

There was also a Character $\times$ Wave interaction, $F(1,314)=13.755, p<.001$, $\eta_{\mathrm{p}}{ }^{2}=.042$. Follow-up analyses indicated that there was a significant increase in the number of female characters in children's reports over time (Wave 1: $M=0.50, S D=0.76$ vs. Wave $3: M=0.70, S D=0.88)$. 


\section{Reporters' Writing About Male and Female Pronouns}

In order to examine whether boys and girls differed in their use of male and female pronouns in their reports, a 2 (gender) $\times 2$ (grade) $\times 2$ (wave) $\times 2$ (pronoun type: male and female) mixed ANOVA was conducted with number of pronouns reported as the dependent variable. Gender and grade were between-subjects variables. Pronoun type and wave were within-subject variables.

The 4-factor ANOVA computed on pronoun type yielded main effects of gender, $F(1,314)=7.446, p<.01, \eta_{p}^{2}=.023$; age, $F(1,314)=28.556, p<.01$, $\eta_{\mathrm{p}}{ }^{2}=.083$; and wave, $F(1,314)=10.348, p<.01, \eta_{\mathrm{p}}{ }^{2}=.032$. In children's reports, more pronouns were used by girls than by boys $(M=1.80, S D=1.89$ vs. $M=1.26, S D=1.83)$; by older children than by younger children $(M=2.22$, $S D=2.24$ vs. $M=1.12, S D=1.46)$; and in Wave 3 than in Wave $1(M=1.87$, $S D=3.04$ vs. $M=1.23, S D=2.15$ ).

There was also a significant Pronoun Type $\times$ Gender interaction, $F(1,314)=$ $7.870, p<.01, \eta_{\mathrm{p}}{ }^{2}=.024$. Follow-up analyses revealed that there were no significant differences between boys and girls in their use of male pronouns. However, girls used significantly more female pronouns than did boys $(M=0.94, S D$ $=1.39$ vs. $M=0.42, S D=1.24$ ).

There was a significant 4-way interaction of Wave $\times$ Pronoun Type $\times$ Grade $\times$ Gender, $F(1,314)=4.303, p<.05, \eta_{\mathrm{p}}{ }^{2}=.014$. As seen in Figure 1 , boys showed the most pronounced difference in using male pronouns over female pronouns during Wave 1; all other groups were similar in their use of male and female pronouns during Wave 1, though older girls did use more pronouns overall. By Wave 3, pronoun usage had increased for all groups; male pronouns were used more than female pronouns for all groups except for older girls who now used more female pronouns than male pronouns.

\section{Reporters' Writing About Male and Female Characters and Stereotyped Behaviors}

In order to examine whether boys and girls reports differed in their use of male versus female characters, and whether the characters the children wrote about engaged in gender-stereotyped behavior, a 2 (gender) $\times 2$ (grade) $\times 2$ (wave) $\times 2$ (character type: male and female) $\times 2$ (behavior type: masculine and feminine) mixed ANOVA was conducted with the number of gender-stereotyped behaviors and traits reported as the dependent variable. Gender and grade were betweensubjects factors. Character type, behavior type, and wave were the within-subject factors. 
5th-6th Graders: Pronouns Reported

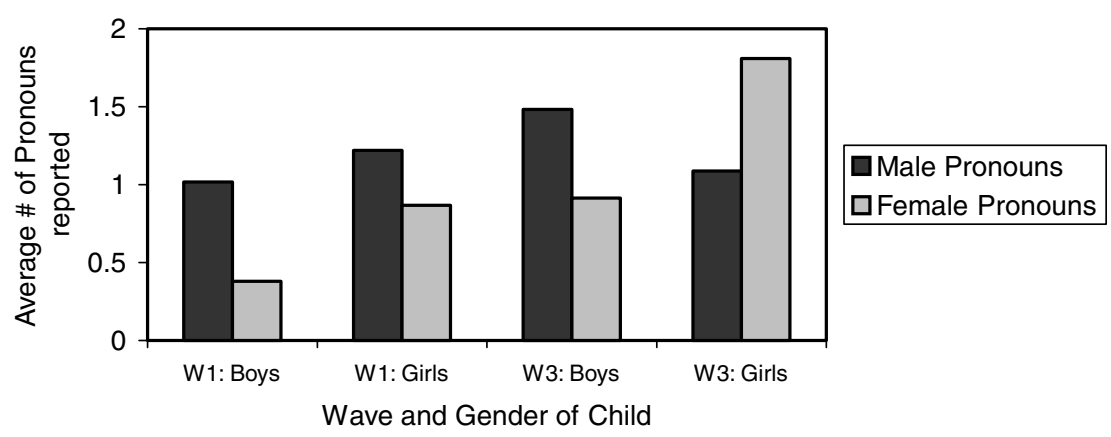

2nd-4th Graders: Pronouns Reported

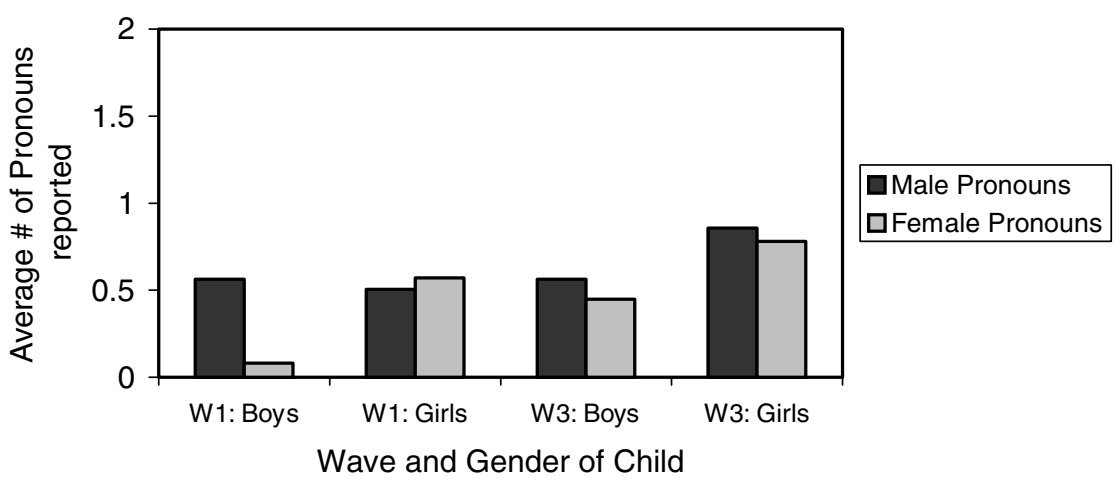

Figure 1. Average number of male and female pronouns reported as a function of grade, gender, and wave.

The 5-factor ANOVA computed on stereotyped behaviors yielded main effects of grade, $F(1,314)=15.934, p<.001, \eta_{\mathrm{p}}{ }^{2}=.048$; character type, $F(1,314)=$ $28.231, p<.001, \eta_{\mathrm{p}}{ }^{2}=.082$; and behavior type, $F(1,314)=35.359, p<.001$, $\eta_{\mathrm{p}}{ }^{2}=.101$. Older children reported more characters and behaviors in their reports than did younger children, $(M=2.07, S D=2.37$ vs. $M=1.65, S D=2.04)$. Children's reports contained more male characters $(M=1.29, S D=1.76)$ than female characters $(M=0.78, S D=1.30)$ and more masculine behaviors than feminine behaviors $(M=1.33, S D=1.74$ vs. $M=0.73, S D=1.20)$. 
The main effect of grade was qualified by a Grade $\times$ Character Type interaction, $F(1,314)=5.059, p<.05, \eta_{p}{ }^{2}=.016$ and by a Grade $\times$ Behavior Type $\times$ Gender interaction, $F(1,314)=6.582, p<.05, \eta_{p}{ }^{2}=.02$. As illustrated in Figure 2, the 3-way interaction revealed that both boys and girls reported masculine behaviors more often than feminine behaviors, but the difference was less pronounced for older girls. The follow-up contrast of grade and character type revealed that although older and younger children reported more male characters than female characters, the difference was more pronounced for older children $(M=1.75, S D=1.99$ vs. $M=0.95, S D=1.51)$ than for younger children $(M=0.98, S D=1.52$ vs. $M=0.66, S D=1.13)$.

The main effect of character type was qualified by a Character Type $\times$ Gender interaction, $F(1,314)=17.131, p<.001, \eta_{\mathrm{p}}{ }^{2}=.052$; a Character Type $\times$ Behavior interaction, $F(1,314)=9.351, p<.01, \eta_{\mathrm{p}}{ }^{2}=.029$; a Character Type $\times$ Wave interaction, $F(1,314)=10.823, p<.01, \eta_{\mathrm{p}}{ }^{2}=.033$, and a Character Type $\times$ Behavior Type $\times$ Wave interaction, $F(1,314)=3.987, p<.05$,

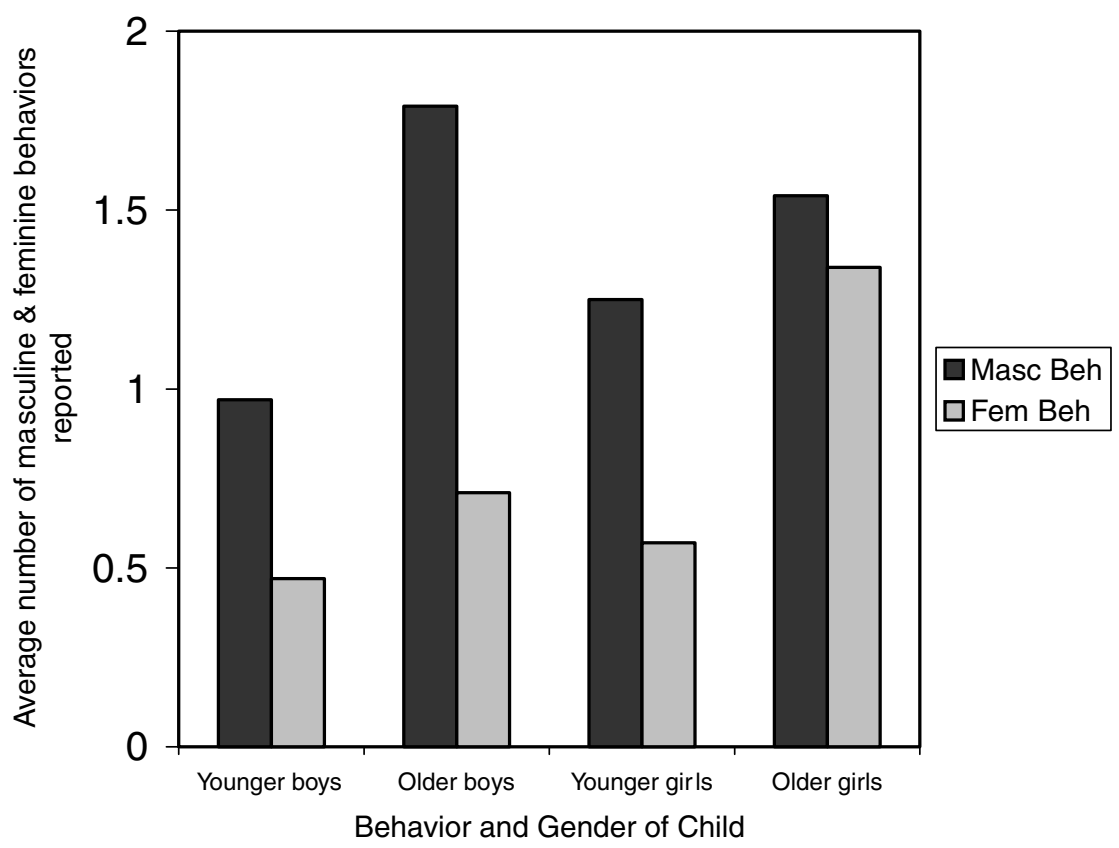

Figure 2. Average number of masculine and feminine behaviors reported as a function of grade and gender. 
$\eta_{\mathrm{p}}{ }^{2}=.013$. As illustrated in Figure 3, masculine behaviors were reported more often than were feminine behaviors for both waves. For Wave 1 only, children wrote more about male characters than female characters. In addition, masculine behaviors were reported more often than were feminine behaviors for male characters, but the difference was less pronounced for female characters. Over time, however, the masculine behaviors reported for female characters increased whereas the masculine behaviors of male characters decreased. The number of feminine behaviors for characters remained relatively constant over time. The Character Type $\times$ Gender interaction revealed that boys reported significantly more male characters than female characters $(M=1.39, S D=1.92$ vs. $M=0.48, S D=1.12)$ but also that girls did not $(M=1.21, S D=1.63$ vs. $M=1.03, S D=1.39)$.

Summary. Male characters and masculine behaviors were reported more often than were female characters and feminine behaviors. Male characters were most likely to be perceived as doing traditionally masculine behaviors, whereas female characters were as likely to be perceived as doing masculine as feminine behaviors. These patterns were more pronounced for boys than for girls and for Wave 1 than for Wave 3.

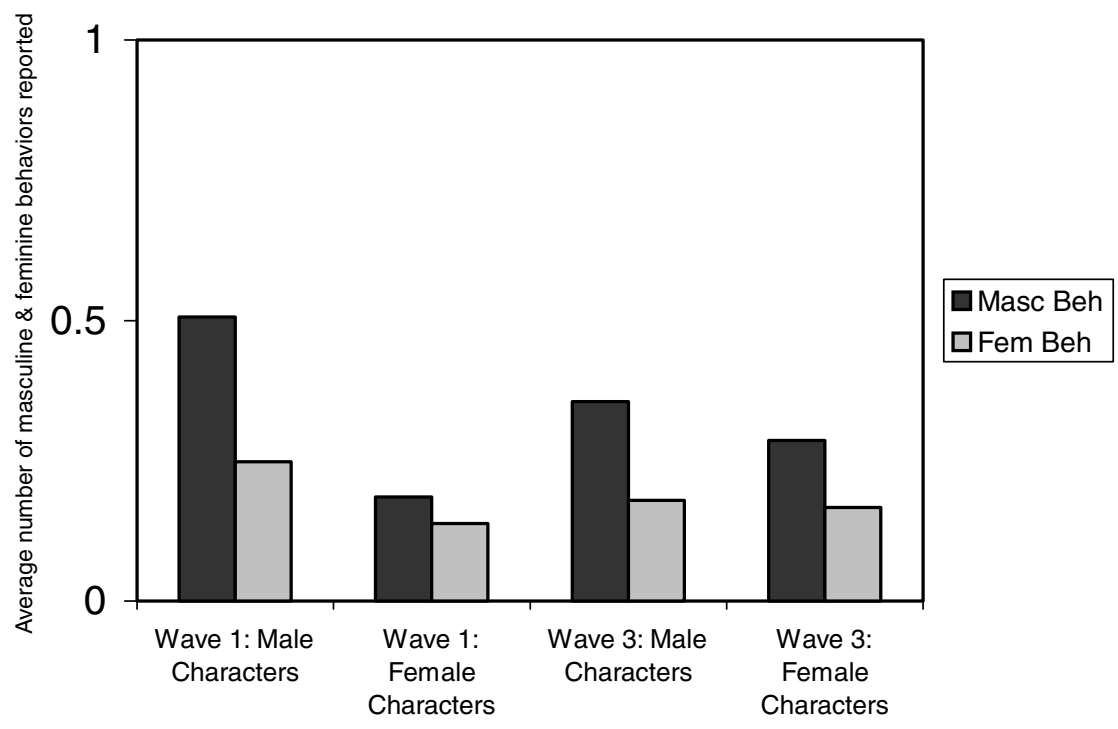

Wave and Gender of Character

Figure 3. Average number of masculine and feminine behaviors reported as a function of wave and gender of character. 


\section{Children's Writings About Male} Versus Female Heroic Actions

We were especially interested in whether children wrote about heroic actions of characters and whether those characters were more likely to be male than female, as is traditionally the case, or if this pattern was changing due to popular programs like The Wild Thornberrys, in which Eliza, the female lead character, often acts heroically. Heroic actions were written about in only 52 reports $(3.2 \%$ of the sample). The largest percentage of heroic actions, $33.9 \%$, came from The Wild Thornberrys; $16.9 \%$ from Hey Arnold!; $11.9 \%$ from Disney's Recess; $10.2 \%$ from Cousin Skeeter; and 6.8\% from Brand Spanking New! Doug.

For this subset of reports, a 3 (gender of hero: male, female, mixed gender) $\times$ 2 (gender) $\times 2$ (grade) between-subjects ANOVA was conducted with heroic action as the dependent variable. We added the group of mixed-gender heroes to this analysis because the heroic actor was sometimes described as a group of characters such as "the kids from Recess," "parents," "teachers," and "Darwin and Eliza." Data from Wave 1 and Wave 3 were collapsed because only 7 children wrote about heroic acts in both waves.

The 3-factor ANOVA computed on heroic actions yielded a main effect for gender of the hero, $F(2,47)=3.63, p<.05, \eta_{\mathrm{p}}{ }^{2}=.134$. Male characters were significantly more likely to be involved in heroic acts than were couples or groups of mixed-gender characters $(M=0.69, S D=0.76$ vs. $M=0.35, S D=$ 0.56). Interestingly, the number of female characters involved in heroic acts was in the middle but not significantly different from males or mixed-gender groups $(M=0.54, S D=0.87)$.

Eliza, from The Wild Thornberrys, was the most-cited character engaged in heroic actions, accounting for about $18 \%$ of all the heroic segments, and another $3.6 \%$ segments contained Eliza and someone else (e.g., Darwin the monkey, Grandfather, and a scientist) engaging in heroic acts. Girls were more likely to write about Eliza's heroic actions (69\%) than were boys (21\%). Parental characters accounted for approximately $5 \%$ of all heroic segments, as did the character Skeeter from Cousin Skeeter and nonspecified kids.

\section{Reporters' Writing About Feelings}

To examine whether boys and girls differed in the number and kinds of explicit feelings expressed, a 2 (gender) $\times 2$ (grade) $\times 2$ (wave) $\times 6$ (feelings: love, happiness, surprise, anger, sadness, and fear) ANOVA was conducted on total number of feelings reported. Gender and grade were between-subjects factors. Wave and feelings were within-subject factors. 
The 4-factor ANOVA computed on feelings yielded main effects of gender, $F(1,314)=13.333, p<.001, \eta_{\mathrm{p}}^{2}=.041$; grade, $F(1,314)=5.932, p<.05$, $\eta_{\mathrm{p}}{ }^{2}=.019$; and feeling type, $F(5,310)=19.349, p<.001, \eta_{\mathrm{p}}{ }^{2}=.238$. As expected, girls reported more overall feelings than did boys $(M=0.46, S D=0.66$ vs. $M=0.24, S D=0.54)$, and older children reported more feelings than did younger children $(M=0.46, S D=0.71$ vs. $M=0.29, S D=0.53)$. Simple comparisons indicated that love $(M=0.12, S D=0.31)$ and anger $(M=0.10$, $S D=0.28)$ were written about significantly more often than were sadness $(M=$ $0.05, S D=0.18)$, happiness $(M=0.04, S D=0.16)$, and fear $(M=0.04, S D=$ $0.17)$, which, in turn, were written about significantly more often than surprise $(M=0.00, S D=0.00)$.

The gender and grade main effects were qualified by a Grade $\times$ Gender interaction, $F(1,314)=4.588, p<.05, \eta_{\mathrm{p}}{ }^{2}=.014$. While there was no difference in boys' reports across age, the reports of 5th- through 6th-grade girls expressed more feelings than the reports of 2 nd- through 4 th-grade girls $(M=0.65, S D=$ 0.71 vs. $M=0.33, S D=0.60)$.

The main effects of gender and feeling type were qualified by a Gender $\times$ Feeling Type interaction, $F(5,310)=2.382, p<.05, \eta_{\mathrm{p}}{ }^{2}=.037$; and a Grade $\times$ Feelings interaction, $F(5,310)=2.321, p<.05, \eta_{\mathrm{p}}{ }^{2}=.036$. Follow-up analyses indicated that girls' reports, more so than boys' reports, contained expressions of love $(M=.16, S D=.36$ vs. $M=.08, S D=.24)$; happiness $(M=.06, S D=.20$ vs. $M=.01, S D=.08)$; and anger $(M=.13, S D=.29$ vs. $M=.07, S D=.25)$. In addition, follow-up analyses indicated that older children's reports, more so than younger children's reports, expressed feelings of love $(M=.17, S D=.40$ vs. $M=.09, S D=.24)$ and sadness $(M=.08, S D=.23$ vs. $M=.03, S D=.13)$. We also analyzed our data to see if girl characters were more likely to be described as expressing feelings than were boy characters. Interestingly, both boy and girl characters were equally likely to be described as expressing feelings of any sort.

\section{The Drench Hypothesis and The Wild Thornberrys}

Because the most cited heroic character was Eliza in The Wild Thornberrys, we further investigated whether the gender patterns we found in the overall sample were also present in the sample of children who chose The Wild Thornberrys as a favorite program. There were 80 children who chose The Wild Thornberrys as their favorite program. Because there were only 9 children who reported it as their favorite program in the reports we sampled from both waves, we averaged those 9 students' scores across waves. We retained the one wave (either Wave 1 or 
Wave 3) for the other students who wrote about The Wild Thornberrys to create one occasion for analysis per child.

To examine whether boys and girls differed in their use of male versus female characters in their reports about The Wild Thornberrys, a 2 (gender) $\times 2$ (grade) $\times 2$ (character type: male and female) mixed ANOVA was conducted, with the number of distinct male and female characters reported as the dependent variable. Gender and grade were between-subjects factors. Character type was the withinsubject factor.

The 3-factor ANOVA computed on sex of character yielded a main effect for character type, $F(1,76)=20.406, p<.001, \eta_{\mathrm{p}}{ }^{2}=.212$. Contrary to the overall patterns presented in the full sample, children wrote about female characters $(M=1.13, S D=0.90)$ more than male characters $(M=.63, S D=0.85)$ when their favorite program was The Wild Thornberrys. This was true for both girls and boys. There was also a main effect of gender $F(1,76)=4.198, p<.05, \eta_{\mathrm{p}}{ }^{2}=$ .052 . Girls wrote about more characters than did boys $(M=2.01, S D=.52$ vs. $M=1.37, S D=1.52$ ).

A similar analysis was conducted with pronoun types as the within-subject factor for The Wild Thornberrys. For pronouns, there was a main effect for gender, $F(1,76)=4.169, p<.05, \eta_{\mathrm{p}}{ }^{2}=.052$; pronoun type, $F(1,76)=9.876, p<.01$, $\eta_{\mathrm{p}}{ }^{2}=.115$; and a marginal main effect for grade, $F(1,76)=3.75, p<.06, \eta_{\mathrm{p}}{ }^{2}=$ .047 . Female pronouns were used more than male pronouns $(M=1.44, S D=2.35$ vs. $M=0.56, S D=1.26)$. Girls used more pronouns than boys $(M=2.60, S D=$ 3.41 vs. $M=1.03, S D=1.90$ ), and older children tended to use more pronouns than did younger children $(M=2.98, S D=3.60$ vs. $M=1.54, S D=2.58)$.

The main effects of pronoun type, grade, and gender were qualified by a Pronoun Type $\times$ Grade $\times$ Gender interaction, $F(1,76)=4.102, p<.05, \eta_{\mathrm{p}}{ }^{2}=.051$. Follow-up analyses indicated that for younger children, even though boys and girls wrote using more female than male pronouns, girls were more likely to use female pronouns than were boys $(M=1.81, S D=2.90$ vs. $M=0.39, S D=$ $0.95)$. By contrast, the difference between younger girls' and boys' reporting of male pronouns was less pronounced $(M=0.20, S D=0.43$ vs. $M=0.38, S D=$ 0.72 ). For older children, boys and girls used more female than male pronouns $(M=1.88, S D=2.21$ vs. $M=1.10, S D=1.94)$.

A third analysis was conducted with masculine and feminine behaviors as the dependent measure. The only significant finding was a main effect for behavior type, $F(1,76)=24.299, p<.001, \eta_{\mathrm{p}}{ }^{2}=.242$. Children wrote more about masculine behaviors than feminine behaviors $(M=1.22, S D=1.76$ vs. $M=0.35$, $S D=0.77)$. Even so, boy and girl characters were equally likely to engage in masculine behaviors. We further analyzed children's responses to The Wild 
Thornberrys to assess whether there was an interaction between gender of character and gendered behavior. However, there was no such interaction. Put another way, female characters engaged in just as many masculine and feminine behaviors as did male characters.

Finally, an analysis was run on feeling type. There were no gender or grade differences in the number of different types of emotions in the children's reports of The Wild Thornberrys. In addition, we did not find any difference in reporting feelings based on the gender of the character. That is, male and female characters were equally likely to be described as having feelings of one kind or another.

Summary. Children who chose The Wild Thornberrys as a favorite program were more likely to write about female characters and female pronouns than they were to write about male characters and male pronouns. The actions that were reported were more likely to be traditionally masculine rather than traditionally feminine behaviors and traits, but girl characters were as likely to engage in masculine behaviors as were boy characters. There was no difference in children's reports of feelings in The Wild Thornberrys.

\section{Choice of Editor}

We hypothesized that girls would send their reports to Kate, the female editor, and that boys would send their reports to Will, the male editor. The dependent variable was scored 0 for Kate and 1 for Will. Using logistic regression, we examined whether gender and grade influenced choice of editor. In Wave 1 and Wave 3, girls were much more likely to send their reports to Kate than were boys (Wave 1: odds ratio $=50.37, p<.001$; Wave 3: odds ratio $=9.77, p<.001$. McNemar's test across waves indicated that only the 2nd- through 4th-grade girls were likely to change choice of editor over time $p<.05$.

\section{Summary}

Overall, both boys and girls chose many of the same educational television programs as favorites. However, by Wave 3, girls were often reporting about programs that featured female leads. Three of the five favorite programs selected by older girls had a female lead character. Boys' reports generally focused on male characters, masculine pronouns, and masculine behaviors and traits, but they did like The Wild Thornberrys, a program featuring a female lead character. 
Girls typically reported about male characters, masculine behaviors, and used masculine pronouns as often as did boys; but girls also included more female characters, feminine pronouns, feminine behaviors, and feelings than did boys. However, by Wave 3, when older girls were selecting female-oriented programs as favorites, older girls favored female over male pronouns and the number of female characters in children's reports had increased.

Although infrequently discussed in children's reports, male characters were no more likely to be called heroes than were female characters, in large part because of reports about Eliza Thornberry. Moreover, boys, particularly older ones, who chose The Wild Thornberrys as their favorite television program used as many female as male characters and pronouns in their reports. Across all programs, boys and girls wrote reports in which male and female characters had more masculine than feminine behaviors; female characters were reported to have more feminine behaviors than were male characters. Boys and girls chose same-sex reporters for posting their reports.

\section{DISCUSSION}

The purpose of this study was to examine gender stereotyping in children's writings about their favorite educational and informational television programs. Prior content analyses have documented the advantage that male characters have over female characters, even in educational programs for young audiences (Barner, 1999; Calvert et al., 1997). Our study demonstrates that this disparity in presentation can carry over into children's reports about educational television programs. Overall, children reported more male than female characters and that is then carried over into their use of more male than female pronouns. These differences are particularly pronounced for preadolescent boys who were less likely to write about female characters than were girls.

Children also wrote mainly about masculine behaviors and traits, but interestingly girl characters were reported as engaging in about the same number of masculine behaviors as did boy characters. Boy characters, however, engaged in fewer feminine behaviors than did girl characters. Girls were more likely than boys to express feelings in their reports, even feelings of anger that are a traditional emotional outlet for boys (Ruble \& Martin, 1998). These findings suggest that traditionally masculine behaviors remain more powerful than traditionally feminine behaviors, and that females can engage in and embrace nontraditional behaviors more readily than can males (Ruble \& Martin, 1998). 
Taken together, our findings support a gender-schematic processing model (Calvert \& Huston, 1987) and a drench hypothesis (Greenberg, 1988) interpretation in children's understanding of educational television programs. That is, children remembered content in gender stereotypical ways, but also remembered nontraditional portrayals of female characters. Although boys generally wrote about male characters and used male pronouns, these differences were reduced and even eliminated when an adventurous heroic girl, such as Eliza Thornberry, was the main character of their favorite program. Girls often wrote about Eliza in their reports, and boys liked this program too, suggesting that what a character does may be as important in boys' viewing choices as is the sex of the character. This presentation meant that male and female characters were equally likely to be recalled as heroic in their actions. The female heroic genre is becoming more popular in television programs, providing more varied ways to think about nontraditional female characters (Calvert et al., 2001). If favorite programs have a greater impact on children, as would be predicted by the drench hypothesis, then having access to even a few of these programs may alter traditional gender schemas, or support nontraditional schemas.

The drench hypothesis and gender schema theory were also useful in interpreting girls' preferences for girl programs. That is, the girls' interest in programs with girl lead characters and the girl online animated editor suggests that girls may seek characters who are similar to their perceptions of self, perhaps because boys and girls use gender schemas as a way to define who they are (Martin \& Halverson, 1981). Like boys, girls saw female characters engaging in as many masculine behaviors as feminine behaviors.

In conclusion, industry beliefs that boys will not watch programs with female leads (Jordan, 1996) are not supported by our data. Girl characters such as Eliza Thornberry are well received by boys when they are perceived as nontraditional in their actions. The implication is that what characters do may be more important than their gender as a gauge of audience interest. Future research should examine additional favorite programs of children, including those that are not necessarily educational and informational.

\section{AUTHOR NOTE}

This research was supported by grants from the Smith Richardson Foundation and the National Science Foundation. We thank the children, teachers, and schools who participated in this project as well as Matthew Hammar, Katherine 
Jacobs, Edward Gonzales, Jr., Alison Kuhl, Mickey Lee, and Sean Lai for their assistance in scoring reports.

\section{REFERENCES}

Barner, M. R. (1999). Sex-role stereotyping in FCC-mandated children's educational television. Journal of Broadcasting \& Electronic Media, 43, 551-564.

Bem, S. (1981). Gender schema theory: A cognitive account of gender typing. Psychological Review, 88, 352-364.

Calvert, S. (1999). Children's journeys through the information age. Boston: McGraw-Hill.

Calvert, S., \& Huston, A. (1987). Television and children's gender schemata. In L. C. Liben \& M. Signorella (Eds.), New directions in child development: Vol. 38. Children's gender schemata: Origins and implications (pp. 75-88). San Francisco: Jossey-Bass.

Calvert, S. L., Kondla, T., Ertel, K., \& Meisel, D. (2001). Young adults' perceptions and memories of a televised woman hero. Sex Roles, 45, 31-52.

Calvert, S. L., \& Kotler, J. A. (in press). Lessons from children's television: The impact of the Children's Television Act on children's learning. Journal of Applied Developmental Psychology.

Calvert, S. L., Kotler, J., Murray, W., Gonzales, E., Savoye, K., Hammack, P., et al. (2002). Children's online reports about educational and informational television programs. In S. L. Calvert, A. B. Jordan, \& R. R. Cocking (Eds.). Children in the digital age: The role of entertainment technologies in development (pp. 165-182). New York: Praeger.

Calvert, S., Stolkin, A., \& Lee, J. (1997, April). Gender and ethnic portrayals in Saturday morning television programs. Poster session presented at the biennial meeting of the Society for Research in Child Development, Washington, DC.

Children's Television Act, 47 U.S.C. §§ 303a, 303b, 394 (1990).

Cordua, G., McGraw, K., \& Drabman, R. (1979). Doctor or nurse: Children's perceptions of sex-typed occupations. Child Development, 50, 590-593.

Eagly, A. H., \& Crowley, M. (1986). Gender and helping behavior: A metaanalytic review of the social psychological literature. Psychological Bulletin, 100, 283-308.

Gerbner, G. (1996, Fall). TV violence and what to do about it. Nieman Reports, $10-12$. 
Greenberg, B. (1988). Some uncommon television images and the drench hypothesis. In S. Oskamp (Ed.), Television as a social issue: Applied social psychology (Annual 8, pp. 88-102) Newberry Park, CA: Sage.

Huston, A. (1983). Sex typing. In E. M. Hetheringon (Ed.), Handbook of child psychology: Socialization, personality, and social development (4th ed., pp. 387-467). New York: Wiley.

Huston, A., Wright, J., Rice, M., Kerkman, D., \& St. Peters, M. (1990). The development of television viewing patterns in early childhood: A longitudinal investigation. Developmental Psychology, 26, 409-420.

Jordan, A. B. (1996). The state of children's television: An examination of quantity, quality, and industry beliefs. (Rep. No. 2). Philadelphia: University of Pennsylvania, Annenberg Public Policy Center.

Kohlberg, L. (1966). A cognitive-developmental analysis of children's sex-role concepts and attitudes. In E. E. Maccoby (Ed.), The development of sex differences (pp. 82-173). Stanford, CA: Stanford University Press.

List, J., Collins, W. A., \& Westby, S. (1983). Comprehension and inferences from traditional and nontraditional sex-role portrayals on television. Child Development, 54, 1579-1587.

Luecke-Aleksa, D., Anderson, D., Collins, P., \& Schmitt, K. (1995). Gender constancy and television viewing. Developmental Psychology, 31, 773-780.

Martin, C. (1990). Attitudes and expectations about children with nontraditional and traditional gender roles. Sex Roles, 22, 151-165.

Martin, C., \& Halverson, C. (1981). A schematic processing model of sextyping and stereotyping in children. Child Development, 52, 1119-1134.

The new Webster's comprehensive dictionary of the English language (Deluxe ed.) (1985). New York: American International Press.

Northrup, C. (1994). Women's bodies, women's wisdom. New York: Bantam.

Ruble, D., \& Martin, C. (1998). Gender development. In W. Damon \& N. Eisenberg (Eds.). Handbook of child psychology: Vol. 3. Social, emotional, and personality development (5th ed., pp. 933-1016). New York: Wiley.

Sternglanz, S. H., \& Serbin, L. A. (1974). Sex-role stereotyping in children's television programs. Developmental Psychology, 10, 710-715.

Wilson, B. J., Smith, S. L., Potter, W. J., Kunkel, D., Linz, D., Colvin, C. M., et al. (2002). Violence in children's television programming: Assessing the risks. Journal of Communication, 52, 5-35.

Zehnder, S. M. (2002). The hero and the shadow: The influence of age and gender on student's plot comprehension, perception of characters, and knowledge of archetypes in the movie Batman Forever. Unpublished master's thesis, Georgetown University, Washington, DC. 
Copyright of Media Psychology is the property of Lawrence Erlbaum Associates and its content may not be copied or emailed to multiple sites or posted to a listserv without the copyright holder's express written permission. However, users may print, download, or email articles for individual use. 